\title{
Pain Control in Latin America: The Optimized Role of Buprenorphine in the Treatment of Cancer and Noncancer Pain
}

\author{
Joseph V. Pergolizzi Jr. · Robert Taylor Jr. · Jo Ann LeQuang · \\ Argelia Lara $\cdot$ Andres Hernandez Ortiz $\cdot$ Miguel A. Ruiz Iban
}

Received: March 26, 2019 / Published online: May 17, 2019

(C) The Author(s) 2019

\begin{abstract}
Pain is a terrible health problem that transcends borders and nationalities, although there may be significant differences among regions regarding pain management. In Latin America (LatAm, composed of the many nations of Central America, South America, Mexico, and the Caribbean), access to healthcare, pain management, and opioid analgesics can vary. Despite an international U.S.-led trend toward greater control in opioid prescribing, the role of opioids in the management of severe pain in LatAm is probably smaller than it should be, as opioid consumption in LatAm overall is low. Buprenorphine is a strong opioidwith certain characteristics that make it a potentially useful analgesic agent in LatAm: it has a unique pharmacology that allows for transdermal administration and a favorable safety profile with a ceiling effect for respiratory depression. It
\end{abstract}

Enhanced Digital Features To view enhanced digital features for this article go to https://doi.org/10.6084/ m9.figshare.8052563.

J. V. Pergolizzi Jr. · R. Taylor Jr. · J. A. LeQuang ( $₫)$ NEMA Research, Inc., Naples, FL, USA

e-mail: joannlequang@gmail.com

A. Lara - A. H. Ortiz

INMCNSZ, UNAM, Mexico City, Mexico

M. A. R. Iban

Hospital Universitario Ramon y Cajal, Madrid, Spain has a well-studied low risk potential for misuse, and there is strong evidence for its safety and efficacy in managing both cancer and noncancer pain in adults. Caregivers and policy makers in LatAm may learn from the U.S. experience with opioids in order to develop protocols to better and safely manage pain, and it is possible that buprenorphine will play a key role.

Keywords: Latin America; Opioid; Opioid use in Latin America; Pain control

\section{INTRODUCTION}

Pain transcends borders. Latin America (LatAm), with a population of about 639 million, is a diverse geographical region facing public health challenges in helping patients who must deal with different forms of moderate to severe pain. Opioid consumption varies among the LatAm countries but ranges from low to moderate based on international standards [1-10 mg/morphine equivalents (ME) per capita annually]. Formularies in LatAm may offer opioid analgesics, and international guidelines discuss the appropriate use of opioids for various painful conditions, but in LatAm access can limit the use of opioids even when indicated. The appropriate role of opioid analgesics for treating cancer and noncancer pain 
has fallen under scrutiny as the United States and nations in Western Europe face the public health crisis of widespread opioid use disorder (OUD). At a time when key opinion leaders in North America may be advocating a much more limited role for opioid pain relievers, the nations of LatAm must evaluate and even consider expanding the role of opioids in the care of pain patients. Lessons learned from the United States may help guide their considerations. Of particular interest is the role of strong opioids in the management of pain of moderate to severe intensity.

A variety of analgesic products are available: paracetamol (acetaminophen), nonsteroidal anti-inflammatory drugs (NSAIDs), and a range of opioid analgesics such as codeine, morphine, oxycodone, and others. Buprenorphine is a strong opioid analgesic with a unique pharmacology that may offer certain advantages over other opioid analgesics in the treatment of certain pain syndromes. This article is based on previously conducted studies and does not contain any studies with human participants or animals performed by any of the authors.

\section{LATIN AMERICA}

For the purposes of this article, Latin America (LatAm) is composed of the many nations in Central America, South America, much of the Caribbean, and Mexico. As such, LatAm is large, populous, and extremely diverse. While recent decades have seen an ongoing migration of the population to urban centers, LatAm retains a large rural population with more limited access to healthcare. There is great racial and ethnic diversity in LatAm. While most LatAm citizens have at least some European ancestry, intermarriage among Europeans, indigenous peoples, and others of African or Asian ancestry has produced a genetically mixed population. Historically, the Spanish who settled in LatAm encouraged conversion to Catholicism (today LatAm is 70\% Roman Catholic) and cultural assimilation (nearly all of LatAm speaks Spanish or Portuguese), but discrimination was dissimilar to that which occurred in the U.S.. For example, racial slavery was not widespread in
LatAm and miscegenation was legal, in that the Spanish seemed to expect mixed-race marriages. The so-called Columbian Exchange initiated when Christopher Columbus transferred a variety of life forms (including humans) to the New World from the Old World had a pronounced effect on LatAm [1], allowing for genomes in LatAm to be evolutionarily novel in that haplotypes have combined in unprecedented ways [2]. Early genetic research has determined that most LatAm individuals today have paternal connections to Europe and maternal connections to indigenous populations [3]. While much work remains to be done, genetics may explain, for example, why LatAm has a comparatively high prevalence of type II diabetes (risk associated with Native American ancestry) [4].

The healthcare system in LatAm is complex, imperfect, and still evolving. While some form of universal healthcare is available in at least eight LatAm countries [5], healthcare resources in many regions may generally be described as being out of alignment with healthcare demand [6]. Universal healthcare is available in Argentina, Brazil, Chile, Colombia, Costa Rica, Guatemala, Mexico, and Brazil [5], but each nation has its own unique system with peculiarities. Colombia made healthcare a constitutional right for its citizens in 1991 and runs a national insurance program with government subsidies. Mexico has two nationally supported systems: one for retired people and the other for the rest of the population, but private insurance is increasingly popular [7]. Brazil's system likewise is a hybrid of a taxpayer-funded health system and private insurance products that are used by about $25 \%$ of the population to supplement care [7]. However, gaps in the system can be daunting. About 30\% of LatAm citizens have no access to healthcare for any number of reasons, including financial restrictions, geographic impediments, and lack of available services [8]. Nevertheless, there appears to be an increased social and political drive to expand and improve health coverage. Some of the challenges facing LatAm healthcare are summarized in Table 1.

Epidemiological data show that LatAm has made and continues to make considerable progress in healthcare [9]. In the last three decades, 
Table 1 Important healthcare challenges faced by LatAm nations moving forward

\begin{tabular}{|c|c|c|}
\hline Challenge & Details & Broader trends \\
\hline $\begin{array}{l}\text { Access to healthcare is } \\
\text { uneven and varies by region } \\
\text { and even within a country }\end{array}$ & $\begin{array}{l}\text { In general, rural citizens have less access to } \\
\text { care than urbanites }\end{array}$ & $\begin{array}{l}\text { General migration in LatAm toward urban } \\
\text { centers but rural populations are still large }\end{array}$ \\
\hline $\begin{array}{l}\text { High levels of acute and/or } \\
\text { infectious diseases }\end{array}$ & These are typical of developing nations & $\begin{array}{l}\text { Poverty and poor sanitation may drive higher } \\
\text { rates of infectious diseases and affect only } \\
\text { portions of LatAm }\end{array}$ \\
\hline $\begin{array}{l}\text { Increasing levels of First- } \\
\text { World health conditions }\end{array}$ & $\begin{array}{l}\text { Rising rates of hypertension, diabetes, } \\
\text { cancer, and obesity }\end{array}$ & $\begin{array}{l}\text { Genetic predisposition to diabetes; high rates } \\
\text { of obesity starting to occur }\end{array}$ \\
\hline Aging population & $\begin{array}{l}\text { Typical of many parts of the world, poses } \\
\text { challenges to healthcare coverage }\end{array}$ & $\begin{array}{l}\text { Aging is partly related to improvements in } \\
\text { overall health and extended longevity }\end{array}$ \\
\hline $\begin{array}{l}\text { Uneven distribution of } \\
\text { healthcare resources }\end{array}$ & $\begin{array}{l}\text { Insufficient numbers of physicians, nurses, } \\
\text { and hospital beds in general }\end{array}$ & Resources tend to conglomerate in big cities \\
\hline $\begin{array}{l}\text { Social and economic } \\
\text { disparities }\end{array}$ & $\begin{array}{l}\text { Indigenous peoples are more likely to live } \\
\text { in poverty }\end{array}$ & $\begin{array}{l}\text { Indigenous people have higher infant } \\
\text { mortality rates than the rest of LatAm }\end{array}$ \\
\hline $\begin{array}{l}\text { Limited use of certain } \\
\text { medications and treatments }\end{array}$ & $\begin{array}{l}\text { Access to more expensive technologies may } \\
\text { be limited; not all treatments are } \\
\text { available in all parts of LatAm }\end{array}$ & $\begin{array}{l}\text { Certain medications, such as cancer drugs and } \\
\text { opioid analgesics, may not be available to all } \\
\text { people in LatAm, even when indicated and } \\
\text { appropriate }\end{array}$ \\
\hline Income inequality & $\begin{array}{l}\text { The richest } 20 \% \text { of LatAm receive about } \\
60 \% \text { of the area's total income, while the } \\
\text { poorest } 20 \% \text { receive about } 3 \%\end{array}$ & $\begin{array}{l}\text { The disparities between rich and poor are } \\
\text { among the starkest in the world and the } \\
\text { poorest poor of LatAm are among the } \\
\text { poorest on earth }\end{array}$ \\
\hline
\end{tabular}

life expectancy has increased by about 9 years, and is now approximately 65 years for men and 74 years for women [10]. The "graying" of LatAm is one aspect of these extended life expectancies and better healthcare, such as "managed" cancer patients. LatAm has a comparatively high rate of healthcare expenditure associated with injury, with about $20 \%$ of all potential years of life lost in LatAm caused by trauma [11]. About $50 \%$ of all potential years of life are lost to some form of noncommunicable disease (such as cardiovascular disease, stroke, or cancer) [11]. As is evident in much of the rest of the world, smoking rates in LatAm are declining overall [12]. In LatAm, an inverse relationship has been observed between income and prevalence of tobacco consumption [12]. Obesity remains a public health crisis in LatAm, where body mass indices (BMI) of 30 or more occur in $37.6 \%$ of citizens of Uruguay (highest) and $13.3 \%$ of Cubans (lowest) [13]. It has been estimated that every 5-point gain in BMI confers on the individual a 30\% greater risk of mortality, typically due to vascular disease, diabetes, cancer, kidney dysfunction, liver disease, or respiratory disorders [14]. Thus, the increasing rates of obesity are a major public health concern.

Pain is prevalent in LatAm. This may be exacerbated by obesity, which is associated with pain, particularly joint-related pain [15]. Obesity-associated inflammation may also induce paroxysmal pain via neural damage [16]. In addition, chronic pain tends to increase with advancing age. As the population of LatAm ages, rates of cancer and obesity increase, and 
the area maintains its relatively high rate of injuries, treating pain safely and effectively will emerge as a growing (and possibly unmet) urgent medical need.

\section{OPIOID ANALGESICS IN LATIN AMERICA}

Pain in LatAm is not always effectively treated because of limited access to opioid analgesics, widespread use of less-effective nonopioid pain relievers, regulatory and legal barriers, a lack of clinician training in opioid prescribing, and cultural reservations among patients about the use of such drugs [17]. Concern about the public health crisis in the United States involving opioids may make clinicians, regulators, politicians, and patients uneasy about the use of opioids as pain relievers when there are nonopioid products available.

Optimal pain control requires analgesic therapy to be individualized to meet each patient's needs; for this, the prescriber must have access to the full armamentarium of pain relievers, including opioids. Medical key opinion leaders in LatAm have recently advocated changes to pain control guidelines that would allow the broader use of opioids in selected cases of chronic noncancer pain [18]. Opioids were advocated for the control of cancer pain by the World Health Organization over a quarter century ago with its now-famous "pain ladder" that called for increasingly strong pharmacological options to address increasingly severe cancer pain intensity levels [19]. About 20-50\% of cancer patients experience pain, and $80 \%$ of patients with advanced-stage cancer have moderate to severe pain $[20,21]$. This pain can occur at multiple sites [22]. Cancer patients experience pain related to the growth of tumors but also pain associated with treatments (chemotherapy-induced peripheral neuropathy [23] and postsurgical pain), and may have unrelated painful conditions as well. Obesity may compound these risks [24].

Large-scale broad epidemiologic studies have not been conducted in LatAm to provide more specific data on pain, its burden to the healthcare system, and opioid use patterns by country or population groups [25]. Opioid consumption is low to moderate in LatAm by international standards, which suggests that much pain is inadequately treated [26]. However, opioids may not be universally available to all indicated patients in LatAm [27]. Where pain is undertreated or ignored, there are usually multiple factors in play, including legal restrictions, regulatory issues, limited access to care, deficits in provider education and training, cultural attitudes, patient prejudices against opioids or pain relief in general, limited or no reimbursement, or other financial restrictions [28]. In some parts of LatAm, opioid analgesics may be considered too expensive for other than very short-term use [27]. It is not known how much the opioid crisis in the United States is shaping the decisions of international prescribers.

\section{THE POTENTIAL ROLE OF BUPRENORPHINE IN LATIN AMERICA}

Buprenorphine is increasingly being explored by leading medical centers around the world as an important opioid analgesic option, in that it is associated with fewer and less intense psychoactive effects compared to other strong opioids, such as oxycodone [29]. Buprenorphine is not particularly sought by drug-seekers as it has been shown to have low "likeability" [30]. Its withdrawal symptoms are typically less severe than those of other strong opioids [31]. Anecdotally, it is known to the authors that in the U.S., where buprenorphine is a Schedule III controlled substance rather than a Schedule II controlled substance such as oxycodone or morphine, some prescribers prefer buprenorphine to other strong opioids such as oxycodone because it has a lower risk for misuse. In addition, the transdermal formulation of buprenorphine provides convenience and may improve patient adherence [32]. Transdermal buprenorphine may be helpful for patients who require strong analgesics but have difficulty swallowing, have a high pill burden, are involved in complicated treatment protocols that already require taking multiple oral drugs, tend toward noncompliance, or are cognitively 
impaired or extremely stressed with their treatment protocol.

Buprenorphine possesses a unique pharmacology in that it acts as a partial agonist at the $\mu$ opioid receptors although it provides analgesia as a full agonist; it also acts on the $\kappa$-opioid receptors [30, 33]. It is more potent than morphine and has a "ceiling effect" for respiratory depression (meaning that beyond a certain dose, the risk of respiratory depression does not increase), but not for analgesia [34]. In humans, buprenorphine undergoes extensive metabolization, with only a small amount of the parent drug excreted by the kidneys $[35,36]$. Most of this metabolism corresponds to $\mathrm{N}$-dealkylation to norbuprenorphine via the cytochrome (CYP)450-3A4/5 enzymes [37, 38]. Buprenorphine and norbuprenorphine are subject to glucuronidation via the UDP-glucuronosyltransferase (UGT) enzymes to buprenorphine-3glucuronide (B3G) and norbuprenorphine-3glucuronide (N3G) [39]. Peak plasma concentrations of norbuprenorphine exceed those of buprenorphine [40]. Originally, the metabolism of buprenorphine to norbuprenorphine was considered an inactivation pathway [41], but subsequent research indicated that it may actually be a pathway to bioactivation instead [39]. Glucuronidination is generally considered a form of detoxification and an inactivation pathway. To date, the pharmacological effects of norbuprenorphine glucuronides remain to be elucidated [39]. Norbuprenorphine is a powerful opioid agonist that appears to be more potent than buprenorphine [42]. Norbuprenorphine has affinities for the $\mu-, \delta$-, and $\kappa$-opioid receptors [43].

The transdermal delivery system for buprenorphine relies on a matrix (patch) to deliver buprenorphine through the skin, avoiding first-pass hepatic metabolism. In many LatAm countries, transdermal buprenorphine is available in low doses $(5,10$, and $20 \mu \mathrm{g} / \mathrm{h})$ that are designed to be applied once every 7 days for prolonged release. The transdermal patch eliminates the issue of patient adherence in that the patient need not remember to take oral medications on a by-the-clock schedule. It is eliminated hepatically ( $2 / 3$ as norbuprenorphine) and renally (1/3) [33]. Buprenorphine is a potent opioid, but when delivered at low doses it can provide adequate analgesia with adverse effects similar to those of other opioids [44].

\section{CLINICAL RESULTS}

The authors were unable to find randomized clinical study data from trials conducted in LatAm, although there are numerous clinical studies on the role of buprenorphine in a variety of painful conditions. The paucity of clinical trials in LatAMm extends beyond buprenorphine and pain management and may reflect an overall low scientific productivity in the region, financial constraints, lack of a clinical infrastructure suitable for running large randomized trials (such as limited numbers of institutional positions), and an expectation that studies be conducted in developed nations [45]. Thus, we present clinical trials from other parts of the world with the expectation that these are relevant to pain patients in LatAm. A review of lowdose transdermal buprenorphine in the treatment of chronic noncancer pain found that the patch $(5,10$, or $20 \mu \mathrm{g} / \mathrm{h})$ was better tolerated than sublingual buprenorphine and provided effective analgesia for patients with osteoarthritis (OA), low back pain, and other forms of chronic nonmalignant pain [46]. Specific study results for transdermal buprenorphine follow.

\section{Long-Range Studies}

In a study of 321 pain patients (mean age $72.4 \pm 13.8$ years, $85.4 \%$ with musculoskeletal pain, mean pain intensity $6.1 \pm 1.2$ ), buprenorphine transdermal patches (5 and $10 \mu \mathrm{g} / \mathrm{h})$ were initiated $(89.7 \%$ of patients started at the lower dose), and patients were followed over 6 months during which noninterventional observational data were collected. Doses stabilized to 5,10 , or $20 \mu \mathrm{g} / \mathrm{h}$ over the course of the study and the average pain intensity decreased at 6 months from $5.1 \pm 1$ (absolute) to $1.0 \pm 1.0$, while pain-related quality of life improved by $97.3 \%$. The lowdose, seven-day transdermal buprenorphine system with stable dose management was 
reported to be associated with a remarkable improvement in the quality of life and pain relief in this elderly population [47].

A randomized double-blind parallel-group multicenter study in Europe evaluated 199 (OA) patients with a 7-day buprenorphine patch or sham patch. The initial active patch was a $5 \mu \mathrm{g} /$ $\mathrm{h}$ patch which could be titrated up to 10 or $20 \mu \mathrm{g} / \mathrm{h}$, as needed over the course of the 6-month study. Rescue medication was available in the form of $0.5-4 \mathrm{~g}$ of paracetamol (acetaminophen) per day. Twelve placebo and seven active-group patients withdrew from the study for lack of effective pain control. Buprenorphine patients had significantly less pain with movement $(p=0.029)$ and significantly improved Patient Global Impression of Change scores $(p=0.017)$. The primary and secondary endpoints of the Western Ontario and McMaster Universities (WOMAC) OA Index for Pain and the WOMAC OA [48] functional scores were statistically similar. Sleep quality improved in both groups.

Transdermal buprenorphine (initiated at $11.7 \mu \mathrm{g} / \mathrm{h}$ and then titrated, as needed, to a maximum of $35 \mu \mathrm{g} / \mathrm{h}$ ) provided effective pain control in 146 real-world patients with moderate to severe chronic noncancer pain over 6 months. Patients experienced significant pain relief over baseline in terms of pain at rest and pain in movement, and had improved quality of life versus baseline [49].

\section{Comparative Studies}

A clinical study of 134 patients with moderate to severe chronic pain associated with $\mathrm{OA}$ compared pain control over 12 weeks using lowdose transdermal buprenorphine patches $(n=69)$ to oral prolonged-release tramadol $(n=65)$. Buprenorphine patches were available at 5,10 , and $20 \mu \mathrm{g} / \mathrm{h}$ and tramadol was administered twice daily at doses of $75,100,150$, and $200 \mathrm{mg}$; maximum doses were $20 \mu \mathrm{g} / \mathrm{h}$ of buprenorphine or $400 \mathrm{mg} /$ day of tramadol. Both groups achieved clinically relevant pain relief over baseline pain scores, and low-dose buprenorphine patches were deemed non-inferior to prolonged-release tramadol tablets.
Adverse events were similar between groups and occurred in $88.4 \%$ of buprenorphine and $78.5 \%$ of tramadol patients. More tramadol than buprenorphine patients discontinued treatment (32\% vs. $20 \%$, respectively). It was reported that $70 \%$ of patients in both groups would prefer the 7-day low-dose transdermal buprenorphine patch to continue their future analgesic therapy. This study also concludes that the effect of 7-day low-dose transdermal buprenorphine was not inferior to that of oral tramadol tablets [50].

Low-dose transdermal buprenorphine was tested in 1160 opioid-experienced patients with chronic moderate-to-severe low back pain using patches of 5,10 , and $20 \mu \mathrm{g} / \mathrm{h}$ buprenorphine compared to an active control group (immediate-release oxycodone $40 \mathrm{mg}$ /day) over 84 days in a double-blind study. The primary study endpoint was the average pain in the last $24 \mathrm{~h}$ at weeks 4,8 , and 12 . This score was significantly lower in patients in the buprenorphine $20 \mu \mathrm{g} / \mathrm{h}$ group compared to patients in the $5 \mu \mathrm{g} / \mathrm{h}$ group; oxycodone was significantly more effective than buprenorphine $5 \mu \mathrm{g} / \mathrm{h} \quad(p<0.001)$. Buprenorphine $20 \mu \mathrm{g} / \mathrm{h}$ was found to be safe and efficacious in controlling chronic low back pain. Adverse events occurred in $77 \%$ of the buprenorphine $20 \mu \mathrm{g} / \mathrm{h}$ group and $73 \%$ of the oral oxycodone $40 \mathrm{mg}$ group. In this study, 1 patient in the buprenorphine group died of causes deemed unrelated to the study drug, and $<1 \%$ of patients experienced a treatmentemergent serious adverse event [51].

In a similar study, the seven-day buprenorphine transdermal system was evaluated in opioid-naïve patients with moderate-to-severe chronic low back pain in an enriched, open-label, randomized, placebo-controlled study. Patients were provided with a buprenorphine 10 or $20 \mu \mathrm{g} / \mathrm{h}$ patch $(n=257)$ or placebo $(n=284)$ and were evaluated for pain control over 12 weeks. At week 12, the buprenorphine group had significantly lower pain scores (least squares mean treatment difference $-0.58, p=0.010$ ). Adverse events were similar between groups (55\% vs. $52 \%$ for buprenorphine and placebo, respectively). In this study, the 7-daybuprenorphine transdermal system showed efficacy and safety in opioid-naïve patients with chronic low back pain [52]. 
A comparative non-inferiority study of transdermal buprenorphine in the treatment of moderate-to-severe musculoskeletal pain $(n=280)$ randomized patients to receive lowdose 7 -day buprenorphine patches $(5,10$, or $20 \mu \mathrm{g} / \mathrm{h})$ or sustained-release oral tramadol (100-400 mg/day) over 8 weeks. Both groups experienced significant pain relief over baseline, and buprenorphine was not inferior to sustained-release tramadol [53].

In an eight-week, double-blind, placebocontrolled trial, transdermal buprenorphine $(10-40 \mu \mathrm{g} / \mathrm{h})$ was more effective than placebo at reducing pain in 78 opioid-experienced pain patients suffering moderate-to-severe low back pain, and these benefits were sustained over a six-month open-label study extension [54].

In a study of 220 patients $\geq 60$ years old with hip and/or knee OA, patients were randomized to be treated with the 7-day transdermal buprenorphine patch plus oral paracetamol (5-25 $\mu \mathrm{g} / \mathrm{h}$ of buprenorphine plus $1000 \mathrm{mg}$ of paracetamol four times a day, $n=110$ ) or cocodamol (two 8/500, two 30/500 mg tablets twice a day, $n=110$ ). Medication was titrated over 10 weeks and then patients were evaluated over 12 weeks. Buprenorphine patches plus oral paracetamol was deemed to be not inferior to co-codamol tablets for pain relief [55].

\section{Other Studies}

In an open-label observational study of 114 patients with severe chronic musculoskeletal pain, low-dose transdermal buprenorphine patches provided effective pain control over 11 weeks with acceptable tolerability [56]. Yarlas and colleagues published results from two randomized controlled trials that found transdermal buprenorphine improved the quality of sleep in both opioid-naïve and opioid-experienced patients suffering from moderate-to-severe chronic low back pain; benefits emerged at about 4 weeks and were maintained over the 12-week course of the study [57].

\section{Buprenorphine for Cancer Pain}

In a phase IV real-world clinical study of 520 patients suffering chronic cancer pain, the four opioids tested (oral morphine, oral oxycodone, transdermal fentanyl, and transdermal buprenorphine) were similarly effective at 28 days in terms of pain control. About $14.4 \%$ of patients were nonresponders to buprenorphine (highest rate), compared to $11.5 \%$ of morphine patients being nonresponders (lowest rate), which was not statistically significant [58]. A study of 62 patients with severe cancer pain were evaluated over 28 days and grouped into those treated with oral morphine, oral oxycodone, transdermal fentanyl, and transdermal morphine. All of the opioids in this study were found to be effective and well tolerated [59]. A Cochrane review and meta-analysis indicated that transdermal buprenorphine might be effective in treating cancer pain patients but that its use would be limited to a subset of patients (responders) [60].

\section{Safety and Adverse Events}

In an Asian open-label observational study of transdermal buprenorphine $(n=114), 78 \%$ of patients reported at least one treatment-emergent adverse event (TEAE), and $22.8 \%$ of patients discontinued treatment because of side effects [56]. In a comparative study of low-dose transdermal buprenorphine $(5,10$, and $20 \mu \mathrm{g} / \mathrm{h})$ and oral sustained-release tramadol, the incidence of adverse events over the 12-week study was similar for the two groups [53]. In a sixmonth study of transdermal buprenorphine $(n=146$, patches from 11.7 to $35 \mu \mathrm{g} / \mathrm{h}), 23$ patients $(15.75 \%)$ discontinued the patch because of adverse events, most of which were related to either the central nervous system or the gastrointestinal system [49].

A post-marketing surveillance study $(n=13,179)$ of patients with a mean treatment duration of 2 months and transdermal buprenorphine doses ranging from 35 to $70 \mu \mathrm{g} /$ $\mathrm{h}$ found that the most commonly reported adverse events were nausea (3.95\%), cutaneous 
reactions $(2.3 \%)$, confusion $(1.91 \%)$, vomiting (1.59\%), and constipation (0.97\%) [61].

Application site reactions have been reported with the use of buprenorphine transdermal systems. Using integrated data from 16 controlled and uncontrolled phase 3 studies involving chronic pain patients $(n=6566)$, the overall incidence of application site reactions was $23.4 \%$, most of which $(98.3 \%)$ could be considered mild to moderate in intensity; $4.4 \%$ led to discontinuation of buprenorphine patch therapy [62]. From a subset of integrated data on double-blind phases of five enriched, placebo-controlled studies $(n=1806)$, the rate of application site reactions was higher in buprenorphine patch patients $(16.6 \%)$ than in patients with a sham patch (12.7\%) [62]. The most commonly reported application site reactions (in both datasets and in data from an international postmarketing safety database) were pruritus, erythema, and rash. Relevant results of this study were that buprenorphine relieved pain in both groups of patients (cancer pain and non-cancer pain) regardless of age, and that the development of tolerance was not relevant throughout this study [62].

\section{Special Populations}

A Cochrane review examined the literature regarding the role of opioid therapy in the treatment of chronic noncancer pain in pediatric patients (children/adolescents), but found no studies that met its rigorous inclusion criteria [63]. A study of 16 pediatric oncology patients treated with transdermal buprenorphine for moderate-to-severe pain on a 72-h schedule with rescue oral tramadol found that $68.75 \%$ of patients responded to transdermal buprenorphine at 2 weeks with a significant decrease in pain over baseline $(p<0.001)$ along with a significant improvement in quality of life [64]. There is anecdotal evidence that transdermal buprenorphine could be of use in children with cancer pain [65], but clinicians must be aware that data on the pediatric use of transdermal buprenorphine are very limited.

Geriatric patients appear to be particularly good candidates for buprenorphine therapy in that buprenorphine dosing need not be adjusted for older versus younger patients. In fact, buprenorphine may be administered to patients with renal dysfunction [30, 66]. Its efficacy and safety for chronic OA pain has been evaluated specifically in older subjects by Uberall et al., who found that in more than 800 subjects 65 years old or older, transdermal buprenorphine was safe and effective [67]. Its pharmacokinetics in older subjects have also been shown to be similar to those of younger subjects [68]. Lowdose transdermal buprenorphine was efficacious in reducing persistent noncancer pain in geriatric patients ( $n=891$, mean age 72.8 years) over 12 weeks, with most patients reporting improvements in quality of life and function (activities of daily living) [67].

Elderly patients in cognitive decline may be undertreated for pain because their ability to articulate their concerns diminishes and they may be unable to adequately describe pain intensity using conventional metrics such as visual analog or numeric scales. (Some special scales for cognitively impaired patients have been created.) Clinicians may have to assess pain by understanding the patient's potential pain etiologies (e.g., osteoarthritis) and observing the patient's behaviors (e.g., facial expressions, vocalizations, changes in interpersonal interactions, and so on). When available, caregivers or family members may be able to offer insight to the clinical team about possible painful conditions. In some cases, an analgesic regimen may be trialed in a patient with cognitive dysfunction suspected of suffering pain to determine if the patient's behaviors reflect pain relief [69].

The pharmacokinetics of buprenorphine in geriatric patients were evaluated in a multipledose open-label parallel-group study of healthy volunteers [68]. The volunteers were grouped by age into a younger group (age 50-60 years) and an older group ( $\geq 75$ years). Two consecutive 7-day buprenorphine $5 \mu \mathrm{g} / \mathrm{h}$ patches were applied to the subjects, and blood samples were taken during the second patch (days $7,8,9,10$, 12 , and 14 , where day 7 corresponded to a predose). The area under the plasma concentration-time curve at steady state $\left(\mathrm{AUC}_{\mathrm{tau}}\right)$ was similar for both age groups (the mean for older 
patients was $9940 \mathrm{pg} / \mathrm{h} / \mathrm{ml}$ and the mean for younger patients was $11,309 \mathrm{pg} / \mathrm{h} / \mathrm{ml}$ ). Adverse events were reported more frequently among the younger than the older patients (216 vs. 164 events, respectively). This suggests that the dosing of transdermal buprenorphine 7-day patches does not need to be adjusted for older patients [68].

\section{DISCUSSION}

LatAm is the large, growing, vibrant, diverse home to over $8 \%$ of the world's population. It is likely to emerge in the coming decades as an economic powerhouse. Its tremendous cultural, genetic, and political diversity makes it difficult to discuss as a single geographic region, but there are some important considerations for LatAm as a whole with respect to pain. Pain is a universal condition and pain control has been put forth by respected international bodies as a fundamental human right $[70,71]$. Pain should not be ignored, particularly since modern medicine has made available to clinicians a myriad of pain-control products. The current public health crisis of opioid abuse in the United States should not fuel opiophobia in LatAm, but rather help guide LatAm prescribers in how to optimize the role of opioids rather than just avoid them. In fact, LatAm may be in a unique and important position to craft opioid policy and practices that support pain control and minimize risk of OUD by considering lessons learned in the United States in the past decades (see Table 2).

Physicians in LatAm have a unique advantage in that they can help to shape their nations' pain control policies in ways that confer analgesic benefits to pain patients without undue public health risk. OUD is a serious concern and must not be taken lightly, but pain is also an important consideration. Unrelenting moderate-to-severe pain can destroy lives, tear apart families, derail careers, contribute to disability, and cause financial devastation. Patients facing untreated pain have a decreased quality of life; suicide rates are higher among those with unrelenting pain [72]. The appropriate pain control regimen can improve patient function and boost quality of life.

The role of strong opioids in pain control is important. This article focused on transdermal buprenorphine, as it appears to be an excellent all-round choice of opioid analgesic for both cancer and noncancer pain. It is a strong, effective drug; it can be safely used in those with impaired renal function and geriatric patients (without dose adjustment); it has a ceiling for respiratory depression; it is not a drug that drugseekers tend to "like" and abuse; and it is available in a transdermal patch system that may confer its own advantages over oral opioids. This is not to say that transdermal buprenorphine should be the only consideration. Pain control regimens should be the result of shared decision-making between prescribers and patients and, in some cases, their families. There are numerous nonpharmacological and pharmacological methods for pain control, and combination therapy is often helpful. Opioid therapy may not be the first-line approach. Opioids may be combined with nonopioids such as NSAIDs for effective pain relief with a net opioid-sparing effect. When it is determined that a patient is indicated for opioids and deemed to be a suitable candidate, opioids should be trialed with a specific "exit plan" in mind, as many patients find opioids ineffective or cannot tolerate opioid-associated side effects. The lowest possible effective dose should be used. For other than short-term use, titration is often required over several days or weeks. Patients may find certain opioids less effective or less tolerable than others; opioid rotation (to another opioid agent) may be helpful in some cases [73]. Opioids may be combined with nonopioid agents for a net opioid-sparing effect.

There is no "one size fits all" solution to pain. Each patient must be reviewed and considered individually and holistically. A very old terminal cancer patient in severe pain at the end of their life is a different case than a younger active patient with moderate occasional knee pain from OA. A patient with a lifelong history of substance abuse and vague pain complaints is a different case than a patient with no such history trying to cope with a few days of 
Table 2 Experiences in the U.S. with opioids and potential lessons to be derived from these experiences

\begin{tabular}{lll}
\hline What happened in the U.S. Underlying problem & Lessons to be learned
\end{tabular}

Opioids were widely prescribed and the U.S. Widespread use of opioids created the became by far one of the greatest consumers of opioids in the world

Opioids were sometimes prescribed before other treatments were considered for pain

Patients sometimes took opioids without understanding their risks for OUD

Patients sometimes took opioids without being aware of the risks or without even knowing they were taking opioids

As opioids become frequently prescribed in a given community, the drugs can be diverted to local non-patients who take the drugs recreationally

With opioids widely accepted and frequently prescribed, drug-seekers could often doctor shop to get multiple prescriptions

Drug seekers could feign symptoms to get opioids. Drug seekers could go to emergency departments and demand opioids for any number of pain complaints perception among prescribers and patients that opioids were relatively harmless, could be taken for mild pain, and were suitable for long-term use even with minimal clinical supervision

Many patients got or could get opioids for relatively minor complaints. This allowed drug seekers to feign minor complaints to get opioids

Patients at elevated risk for OUD were sometimes prescribed opioids and found themselves struggling with addiction

Patients were sometimes prescribed drugs, did not realize they were opioids, and may have taken them carelessly

Those who use heroin and other illicit drugs often prefer pharmaceutical-grade products for their purity and strength. They are easier to obtain when the drugs are plentiful and readily prescribed in a community

Drug seekers and drug dealers could systematize the obtaining of opioid prescriptions; prescription pads are sometimes stolen and sold to dealers

Drug seekers may identify and target physicians and hospitals that liberally prescribed opioids
Prescribers and patients should learn about opioids, their appropriate role, and how to take them. Opioids should never be started without a clear "exit plan.” Patients taking opioids should be under close clinical supervision. Opioids should be used for as short a time as possible

Opioids are not necessarily the first or only pain control option. Nonopioid analgesics are often effective; combination therapy (with nonopioid plus a small amount of opioid analgesic) can be effective

Risks for OUD are well known and can be used to stratify patients for risk. A patient-provider written agreement may be helpful in spelling out the risks of OUD

Patients must be educated by their clinicians as to what opioids are, their risks, their side effects, and their potential benefits

Extensive prescribing appears to be associated with opioid misuse.

When opioids are indicated, prescribers can select less "likable" products (such as buprenorphine), abuse-deterrent formulations, or transdermal systems (which make it more difficult to extract the drug for misuse)

The use of prescription databases and the sharing of information can help flag potential abusers. Hospitals should share information about drug-seekers

Opioids should be prescribed prudently and carefully, if at all. A variety of tools exist to help identify drug seekers and aberrant drug-seeking behaviors. Physicians treating pain should explore multiple approaches to pain control before trialing opioids 
Table 2 continued

\begin{tabular}{|c|c|c|}
\hline What happened in the U.S. & Underlying problem & Lessons to be learned \\
\hline $\begin{array}{l}\text { Some people suffer moderate-to-severe pain } \\
\text { but cannot get pain medication; they turn } \\
\text { to street drugs, including opioids }\end{array}$ & $\begin{array}{l}\text { Many people with OUD are legitimate pain } \\
\text { patients who have exhausted their } \\
\text { healthcare resources or who have lately } \\
\text { been tapered off opioids }\end{array}$ & $\begin{array}{l}\text { Pain should be taken seriously and always } \\
\text { treated, even if opioids are not the first } \\
\text { drug of choice }\end{array}$ \\
\hline $\begin{array}{l}\text { Some people have problems apart from pain } \\
\text { compelling them to take drugs and/or } \\
\text { alcohol, such as mental health conditions } \\
\text { or poor coping skills }\end{array}$ & $\begin{array}{l}\text { Many people with OUD have a "dual } \\
\text { diagnosis" or concomitant mental health } \\
\text { disorder }\end{array}$ & $\begin{array}{l}\text { Physicians should get to know pain patients } \\
\text { and be alert to possible mental health } \\
\text { comorbidities, such as depression. Some } \\
\text { people take opioids to "chemically cope" } \\
\text { with stress, boredom, feelings of being } \\
\text { overwhelmed, or mental health } \\
\text { conditions }\end{array}$ \\
\hline $\begin{array}{l}\text { Drug abusers often take many different } \\
\text { types of drugs and tend to take the drugs } \\
\text { most readily available; in the U.S., these } \\
\text { drugs were often opioids }\end{array}$ & $\begin{array}{l}\text { Polydrug abuse is common among drug } \\
\text { abusers. Drug abusers may have a "drug of } \\
\text { preference" but appear willing to migrate } \\
\text { to other drugs when that preferred drug } \\
\text { becomes unavailable or prohibitively } \\
\text { expensive. Thus, the drugs abused are } \\
\text { typically those available and affordable }\end{array}$ & $\begin{array}{l}\text { Physicians should ask patients about all of } \\
\text { the drugs they take, including illicit ones. } \\
\text { Drug testing may be helpful. Patients } \\
\text { actively abusing other drugs or alcohol are } \\
\text { at high risk for OUD }\end{array}$ \\
\hline $\begin{array}{l}\text { Many people with OUD are actually } \\
\text { physically and psychologically dependent } \\
\text { on opioids and have trouble giving them } \\
\text { up }\end{array}$ & $\begin{array}{l}\text { Opioids can cause potentially severe } \\
\text { withdrawal symptoms if stopped abruptly. } \\
\text { This state (being "dope sick") is dreaded } \\
\text { by those with OUD and can cause opioid } \\
\text { abusers to keep using opioids, even after } \\
\text { the drug has lost its appeal. Rehabilitation } \\
\text { has a low success rate, and relapse is } \\
\text { common. Even when rehabilitation } \\
\text { programs are available, rehabilitation } \\
\text { centers can be prohibitively expensive }\end{array}$ & $\begin{array}{l}\text { Physicians should be educated about all } \\
\text { aspects of OUD and find community } \\
\text { resources to help addicted individuals } \\
\text { who want to overcome their opioid } \\
\text { addiction (for referral). Opioid } \\
\text { maintenance therapy may be an option } \\
\text { for some patients. Some drugs, such as } \\
\text { lofexidine, can help mitigate withdrawal } \\
\text { symptoms. Tapering and discontinuing } \\
\text { opioids should be done with the full } \\
\text { knowledge of the patient and in a } \\
\text { stepwise, systematic way }\end{array}$ \\
\hline
\end{tabular}

Many of these lessons learned are now being applied in the United States

$O U D$ opioid use disorder

postsurgical pain in the hospital setting. Physicians must be advised that, just as each case is unique, each case changes over time. Risk factors for opioid use disorder may be described as dynamic [74]. Physicians and other clinicians should develop relationships of trust with their pain patients, utilize strategies of shared decision-making to find the most appropriate solutions for the pain of each individual, and monitor patients closely to be sure that pain control is effective and its side effects are tolerable. As such, patient education as well as provider training are crucial.

\section{CONCLUSION}

Pain in LatAm may be undertreated, but learning from the U.S. experience with opioids may help guide the diverse nations of LatAm toward a better opioid policy that treats pain effectively 
without encouraging opioid abuse. There are many reasons that opioids are underutilized in LatAm compared to other parts of the world, including regulations, culture, and accessability. Buprenorphine may be a particularly useful opioid for LatAm patients in that it has a unique pharmacology (ceiling effect for respiratory depression), is appropriate for geriatric as well as younger patients without dosing adjustments, is less well "liked" by drug seekers than other strong opioids, and is available in a transdermal system that may provide enhanced patient convenience and possibly drive better compliance. Pain should not be ignored, and finding better pain control solutions is a global concern.

\section{ACKNOWLEDGEMENTS}

Funding. No funding or sponsorship was received for this study or the publication of this article.

Authorship. All named authors meet the International Committee of Medical Journal Editors (ICMJE) criteria for authorship for this article, take responsibility for the integrity of the work as a whole, and have given their approval for this version to be published.

Disclosures. Joseph V. Pergolizzi, Jr. is a member of the journal's Editorial Board. Robert Taylor, Jr., Jo Ann LeQuang, Argelia Lara, Andres Hernandez Ortiz and Miguel A. Ruiz Iban have nothing to disclose.

Compliance with Ethics Guidelines. This article is based on previously conducted studies and does not contain any studies with human participants or animals performed by any of the authors.

Open Access. This article is distributed under the terms of the Creative Commons Attribution-NonCommercial 4.0 International License (http://creativecommons.org/licenses/ by-nc/4.0/), which permits any noncommercial use, distribution, and reproduction in any medium, provided you give appropriate credit to the original author(s) and the source, provide a link to the Creative Commons license, and indicate if changes were made.

\section{REFERENCES}

1. Ruiz-Linares A, Adhikari K, Acuna-Alonzo V, et al. Admixture in Latin America: geographic structure, phenotypic diversity and self-perception of ancestry based on 7,342 individuals. PLoS Genet. 2014;10(9):e1004572.

2. Norris ET, Wang L, Conley AB, et al. Genetic ancestry, admixture and health determinants in Latin America. BMC Genom. 2018;19(Suppl 8):861.

3. Carvajal-Carmona L, Soto I, Pineda N, et al. Strong Amerind/white sex bias and a possible Sephardic contribution among the founders of a population in Northwest Colombia. Am J Hum Genet. 2000;67(5):1287-95.

4. Williams R, Long J, Hanson R, Sievers M, Knowler W. Individual estimates of European admixture associated with lower body-mass index, plasma glucose, and prevalence of types 2 diabetes in Pima Indians. Am J Hum Genet. 2000;66:527-38.

5. World Bank. News: Universal healthcare on the rise in Latin America. 2013. http://www.worldbank.org/ en/news/feature/2013/02/14/universal-healthcarelatin-america. Accessed Dec 20, 2018.

6. Atun R, de Andrade LO, Almeida G, et al. Healthsystem reform and universal health coverage in Latin America. Lancet (London, England). 2015;385(9974):1230-47.

7. Ernst Young. Latin American insurance outlook. $2017 . \quad$ https://www.ey.com/Publication/ vwLUAssets/ey-2017-latin-american-insuranceoutlook/\$FILE/ey-2017-latin-american-insuranceoutlook.pdf. Accessed 13 May 2019.

8. Ramirez J. These are the five health challenges facing Latin America. 2016. https://www.weforum. org/agenda/2016/06/these-are-the-5-healthchallenges-facing-latin-america/. Accessed 20 Dec 2018.

9. Barreto S, Miranda J, Figueroa J, et al. Epidemiology in Latin America and the Caribbean: current situation and challenges. Int $\mathrm{J}$ Epidemiol. 2012;41:557-71.

10. McCarthy M. Boom in Latin American and Caribbean elderly population. Region's health systems have 10 years to prepare for rising number of 
elderly, report warns. Lancet. 2004;363(9407):458-9.

11. Rodriguez T, Malvezzi M, Chatenoud L, et al. Trends in mortality from coronary heart and cerebrovascular diseases in the Americas: 1970-2000. Heart (British Cardiac Society). 2006;92(4):453-60.

12. Bardach A, Perdomo HA, Gandara RA, Ciapponi A. Income and smoking prevalence in Latin America: a systematic review and meta-analysis. Pan Am J Publ Health. 2016;40(4):263-71.

13. Al Snih S, Graham JE, Kuo YF, Goodwin JS, Markides KS, Ottenbacher KJ. Obesity and disability: relation among older adults living in Latin America and the Caribbean. Am J Epidemiol. 2010;171(12):1282-8.

14. Whitlock G, Lewington S, Sherliker P, et al. Bodymass index and cause-specific mortality in 900000 adults: collaborative analyses of 57 prospective studies. Lancet. 2009;373(9669):1083-96.

15. Narouze S, Souzdalnitski D. Obesity and chronic pain: systematic review of prevalence and implications for pain practice. Reg Anesth Pain Med. 2015;40(2):91-111.

16. Hozumi J, Sumitani M, Matsubayashi Y, et al. Relationship between neuropathic pain and obesity. Pain Res Manag. 2016;2016:2487924.

17. Garcia CA, Santos Garcia JB, Rosario MD, et al. Undertreatment of pain and low use of opioids in Latin America. Pain Manag. 2018;8(3):181-96.

18. Lara-Solares A, Aguayo Zamora C, Amescua Garcia $\mathrm{C}$, et al. Latin-American guidelines for opioid use in chronic nononcologic pain. Pain Manag. 2017;7(3):207-15.

19. World Health Organization. WHO's pain ladder for adults. $1988 . \quad$ http://www.who.int/cancer/ palliative/painladder/en/. Accessed 7 May, 2013.

20. Mitra R, Jones S. Adjuvant analgesics in cancer pain: a review. Am J Hospice Palliat Care. 2012;29(1):70-9.

21. Vardy J, Agar M. Nonopioid drugs in the treatment of cancer pain. J Clin Oncol. 2014;32(16):1677-90.

22. Wiffen PJ, Wee B, Moore RA. Oral morphine for cancer pain. Cochrane Database Syst Rev. 2013;7:CD003868.

23. LeQuang J, Pergolizzi J. Chemotherapy-induced peripheral neuropathy: review of clinical studies. Boca Raton: CRC Press; 2012.
24. van Helmond N, Timmerman H, van Dasselaar NT, et al. High body mass index is a potential risk factor for persistent postoperative pain after breast cancer treatment. Pain Phys. 2017;20(5):E661-71.

25. Garcia J. Change Pain Latin America-new initiative established to enhance management of patients with chronic pain in Latin America. Braz J Anesthesiol. 2014;64:140-2.

26. Cleary J, De Lima L, Eisenchlas J, Radbruch L, Torode J, Cherny NI. Formulary availability and regulatory barriers to accessibility of opioids for cancer pain in Latin America and the Caribbean: a report from the Global Opioid Policy Initiative (GOPI). Ann Oncol. 2013;24(Suppl 11):xi41-50.

27. Ruiz Iban MA, Benavides J, Forero JP, et al. Use of strong opioids for chronic pain in osteoarthritis: an insight into the Latin American reality. Expert Rev Clin Pharmacol. 2018;11(1):47-59.

28. De Lima L, Pastrana T. Evaluation of the effectiveness of workshops on the availability and rational use of opioids in Latin America. J Palliat Med. 2016;19(9):964-71.

29. Wesson DR, Smith DE. Buprenorphine in the treatment of opiate dependence. J Psychoactive Drugs. 2010;42(2):161-75.

30. Pergolizzi JV Jr, Scholten W, Smith KJ, LeightonScott J, Willis JC, Henningfield JE. The unique role of transdermal buprenorphine in the global chronic pain epidemic. Acta Anaesthesiol Taiwan. 2015;53(2):71-6.

31. Johnson RE, Fudala PJ, Payne R. Buprenorphine: considerations for pain management. J Pain Symptom Manage. 2005;29(3):297-326.

32. Budd K. Buprenorphine and the transdermal system: the ideal match in pain management. Int J Clin Pract Suppl. 2003;133:9-14 (discussion 23-14).

33. Pergolizzi J, Aloisi AM, Dahan A, et al. Current knowledge of buprenorphine and its unique pharmacological profile. Pain Pract. 2010;10(5):428-50.

34. Dahan A. Opioid-induced respiratory effects: new data on buprenorphine. Palliat Med. 2006;20(Suppl 1):s3-8.

35. Zacny JP, Conley K, Galinkin J. Comparing the subjective, psychomotor and physiological effects of intravenous buprenorphine and morphine in healthy volunteers. J Pharmacol Exp Ther. 1997;282(3):1187-97.

36. Moody DE, Chang Y, Huang W, McCance-Katz EF. The in vivo response of novel buprenorphine 
metabolites, M1 and M3, to antiretroviral inducers and inhibitors of buprenorphine metabolism. Basic Clin Pharmacol Toxicol. 2009;105(3):211-5.

37. Armstrong SC, Cozza KL. Pharmacokinetic drug interactions of morphine, codeine, and their derivatives: theory and clinical reality. Part II. Psychosomatics. 2003;44(6):515-20.

38. DePriest AZ, Puet BL, Holt AC, Roberts A, Cone EJ. Metabolism and disposition of prescription opioids: a review. Forensic Sci Rev. 2015;27(2):115-45.

39. Brown S, Holtzman MJ, Kim TH, Kharasch E. Buprenorphine metabolites, buprenorphine-3-glucuronide and norbupenorphine-3-glucuronide, are biologically active. Anesthesiology. 2011;115:1251-60.

40. Moody DE, Slawson MH, Strain EC, Laycock JD, Spanbauer AC, Foltz RL. A liquid chromatographicelectrospray ionization-tandem mass spectrometric method for determination of buprenorphine, its metabolite, norbuprenorphine, and a coformulant, naloxone, that is suitable for in vivo and in vitro metabolism studies. Anal Biochem. 2002;306(1):31-9.

41. Ohtani M, Kotaki H, Sawada Y, Iga T. Comparative analysis of buprenorphine- and norbuprenorphineinduced analgesic effects based on pharmacokinetic-pharmacodynamic modeling. J Pharmacol Exp Ther. 1995;272(2):505-10.

42. Ohtani M, Kotaki H, Nishitateno K, Sawada Y, Iga T. Kinetics of respiratory depression in rats induced by buprenorphine and its metabolite, norbuprenorphine. J Pharmacol Exp Ther. 1997;281(1):428-33.

43. Huang P, Kehner GB, Cowan A, Liu-Chen LY. Comparison of pharmacological activities of buprenorphine and norbuprenorphine: norbuprenorphine is a potent opioid agonist. J Pharmacol Exp Ther. 2001;297(2):688-95.

44. Pergolizzi J, Raffa R, Taylor R. Low-dose transdermal buprenorphine system: an update. Pain Eur. 2012;1:8-9.

45. Ciocca DR, Delgado G. The reality of scientific research in Latin America; an insider's perspective. Cell Stress Chaperones. 2017;22(6):847-52.

46. Plosker GL. Buprenorphine 5, 10 and $20 \mu \mathrm{g} / \mathrm{h}$ transdermal patch: a review of its use in the management of chronic non-malignant pain. Drugs. 2011;71(18):2491-509.

47. Uberall MA, Muller-Schwefe GH. Long-term treatment of chronic pain with low-dose 7-day buprenorphine transdermal patch. Observational data from elderly patients of pain relief and quality of life. MMW Fortschr Med. 2013;155(Suppl 3):87-96.

48. Breivik H, Ljosaa TM, Stengaard-Pedersen K, et al. A 6-months, randomised, placebo-controlled evaluation of efficacy and tolerability of a low-dose 7-day buprenorphine transdermal patch in osteoarthritis patients naive to potent opioids. Scand J Pain. 2010;1(3):122-41.

49. Gatti A, Dauri M, Leonardis F, et al. Transdermal buprenorphine in non-oncological moderate-tosevere chronic pain. Clin Drug Investig. 2010;30(Suppl 2):31-8.

50. Karlsson M, Berggren AC. Efficacy and safety of lowdose transdermal buprenorphine patches $(5,10$, and $20 \mathrm{microg} / \mathrm{h}$ ) versus prolonged-release tramadol tablets $(75,100,150$, and $200 \mathrm{mg}$ ) in patients with chronic osteoarthritis pain: a 12-week, randomized, open-label, controlled, parallel-group noninferiority study. Clin Ther. 2009;31(3):503-13.

51. Steiner D, Munera C, Hale M, Ripa S, Landau C. Efficacy and safety of buprenorphine transdermal system (BTDS) for chronic moderate to severe low back pain: a randomized, double-blind study. J Pain. 2011;12(11):1163-73.

52. Steiner DJ, Sitar S, Wen W, et al. Efficacy and safety of the seven-day buprenorphine transdermal system in opioid-naive patients with moderate to severe chronic low back pain: an enriched, randomized, double-blind, placebo-controlled study. J Pain Symptom Manage. 2011;42(6):903-17.

53. Leng X, Li Z, Lv H, et al. Effectiveness and safety of transdermal buprenorphine versus sustained-release tramadol in patients with moderate to severe musculoskeletal pain: an 8-week, randomized, double-blind, double-dummy, multicenter, activecontrolled, noninferiority study. Clin J Pain. 2015;31(7):612-20.

54. Gordon A, Callaghan D, Spink D, et al. Buprenorphine transdermal system in adults with chronic low back pain: a randomized, double-blind, placebo-controlled crossover study, followed by an open-label extension phase. Clin Ther. 2010;32(5):844-60.

55. Conaghan PG, O'Brien CM, Wilson M, Schofield JP. Transdermal buprenorphine plus oral paracetamol vs an oral codeine-paracetamol combination for osteoarthritis of hip and/or knee: a randomised trial. Osteoarthritis Cartilage. 2011;19(8):930-8.

56. Yoon DH, Bin SI, Chan SK, et al. Effectiveness and tolerability of transdermal buprenorphine patches: a multicenter, prospective, open-label study in Asian patients with moderate to severe chronic 
musculoskeletal pain. BMC Musculoskelet Dis. 2017;18(1):337.

57. Yarlas A, Miller K, Wen W, et al. Buprenorphine transdermal system improves sleep quality and reduces sleep disturbance in patients with moderate-to-severe chronic low back pain: results from two randomized controlled trials. Pain Pract. 2015;16:345-58.

58. Corli O, Floriani I, Roberto A, et al. Are strong opioids equally effective and safe in the treatment of chronic cancer pain? A multicenter randomized phase IV 'real life' trial on the variability of response to opioids. Ann Oncol. 2016;27(6):1107-15.

59. Nosek K, Leppert W, Nosek H, Wordliczek J, Onichimowski D. A comparison of oral controlledrelease morphine and oxycodone with transdermal formulations of buprenorphine and fentanyl in the treatment of severe pain in cancer patients. Drug Des Dev Ther. 2017;11:2409-19.

60. Schmidt-Hansen M, Taubert M, Bromham N, Hilgart JS, Arnold S. The effectiveness of buprenorphine for treating cancer pain: an abridged Cochrane review. BMJ Support Palliat Care. 2016;6(3):292-306.

61. Griessinger N, Sittl R, Likar R. Transdermal buprenorphine in clinical practice-a post-marketing surveillance study in 13,179 patients. Curr Med Res Opin. 2005;21(8):1147-56.

62. Wen W, Lynch SY, Munera C, Swanton R, Ripa SR, Maibach H. Application site adverse events associated with the buprenorphine transdermal system: a pooled analysis. Expert Opin Drug Saf. 2013;12(3):309-19.

63. Cooper TE, Fisher E, Gray AL, et al. Opioids for chronic non-cancer pain in children and adolescents. Cochrane Database Syst Rev (Online). 2017;7:2538.

64. Ruggiero A, Coccia P, Arena R, et al. Efficacy and safety of transdermal buprenorphine in the management of children with cancer-related pain. Pediatr Blood Cancer. 2013;60(3):433-7.

65. Attina G, Ruggiero A, Maurizi P, Arlotta A, Chiaretti A, Riccardi R. Transdermal buprenorphine in children with cancer-related pain. Pediatr Blood Cancer. 2009;52(1):125-7.

66. Pergolizzi JV, Raffa RB, Marcum Z, Colucci S, Ripa SR. Safety of buprenorphine transdermal system in the management of pain in older adults. Postgrad Med. 2017;129(1):92-101.

67. Uberall MA, Muller-Schwefe GH. Low-dose 7-day transdermal buprenorphine in daily clinical practice-perceptions of elderly patients with moderate non-malignant chronic pain. Curr Med Res Opin. 2012;28(10):1585-95.

68. Al-Tawil N, Odar-Cederlof I, Berggren AC, Johnson HE, Persson J. Pharmacokinetics of transdermal buprenorphine patch in the elderly. Eur J Clin Pharmacol. 2013;69(2):143-9.

69. Cravello L, Di Santo S, Varrassi G, et al. Chronic pain in the elderly with cognitive decline: a narrative review. Pain Ther. 2019. https://doi.org/10. 1007/s40122-019-0111-7.

70. Brennan F, Carr DB, Cousins M. Pain management: a fundamental human right. Anesth Analg. 2007;105(1):205-21.

71. Daher M. Pain relief is a human right. Asian Pac J Cancer Prevent APJCP. 2010;11(Suppl 1):97-101.

72. Hooley JM, Franklin JC, Nock MK. Chronic pain and suicide: understanding the association. Curr Pain Headache Rep. 2014;18(8):435.

73. Nalamachu SR. Opioid rotation in clinical practice. Adv Ther. 2012;29(10):849-63.

74. Pergolizzi JV Jr, Gharibo C, Passik S, et al. Dynamic risk factors in the misuse of opioid analgesics. J Psychosom Res. 2012;72(6):443-51. 